\title{
Iron availability and the release of iron-complexing ligands by Emiliania huxleyi
}

\author{
Marie Boye, Constant M.G. van den Berg* \\ Oceanography Laboratories, Department of Earth Science, University of Liverpool, Bedford Street North, Box 147, Liverpool L69 7ZL, UK
}

Received 18 March 1999; accepted 27 January 2000

\begin{abstract}
The ubiquitous algal species, Emiliania huxleyi, was incubated in sea water supplemented only with nitrate and phosphate ( $\mathrm{N}$ and $\mathrm{P}$ ) without chelating agents to control metal speciation. Growth was slow in a "low-iron" culture containing $1.3 \mathrm{nM}$ iron and was found to be iron-limited, growth-accelerating when a 1-nM iron addition was made. The growth rate in a "high-iron" culture (5.4 nM iron) was greater, reaching 0.4 div day $^{-1}$ but this culture too was found to have become iron-limited when a 9-nM iron addition was made on day 17 of the incubation. Both cultures were found to release iron-complexing ligands in excess of the iron concentration, $6 \mathrm{nM}$ in the low-iron culture, and $10 \mathrm{nM}$ in the high-iron culture. More ligands were produced after the iron addition taking the ligand concentration to $11 \mathrm{nM}$ in the low-iron culture. The data show that the ligands are released in response to the iron addition, when at least some of the iron had already been taken up. This type of release is contrary to the concept of a siderophore, which is supposed to be released in periods of lack of iron; however the increase in the ligand concentration is similar to that released by the natural community in response to the iron addition in the IRON-EX II experiment [Rue, E.L., Bruland, K.W., 1997. The role of organic complexation on ambient iron chemistry in the equatorial Pacific Ocean and the response of a mesoscale iron addition experiment. Limnol. Oceanogr. 42, 901-910]. The enhanced growth in the cultures when more iron was added indicated that the organically complexed iron present in the cultures was not immediately available to the organisms (or at least not at sufficiently high rate), and that the organisms responded to freshly added, inorganic, iron. (C) 2000 Elsevier Science B.V. All rights reserved.
\end{abstract}

Keywords: iron limitation; Emiliania huxleyi; sea water; complexation

\section{Introduction}

The iron limitation hypothesis suggests that primary productivity in waters remote of land, containing high concentrations of nutrients and low levels of chlorophyll, is limited by low levels of iron (Martin and Fitzwater, 1988; Martin et al., 1989, 1990, 1991).

\footnotetext{
* Corresponding author. Tel.: +44-151-794-4096; fax: +44151-794-4099.

E-mail address: sn35@liv.ac.uk (C.M.G. van den Berg).
}

The validity of this hypothesis was demonstrated by the increased phytoplankton productivity obtained when a patch of the ocean was fertilized with iron (Martin et al., 1994; Coale et al., 1996).

The iron hypothesis has been modified by the finding that most of the dissolved iron in the oceanic water column is strongly complexed by organic matter (Gledhill and van den Berg, 1994; Rue and Bruland, 1995, 1997; van den Berg, 1995). Growth limitation of oceanic algae occurs at inorganic iron concentrations of only a few pM (Sunda and Hunts- 
man, 1995), whereas dissolved iron concentrations are on the order of $50-100 \mathrm{pM}$ in remote oceanic surface waters (Johnson et al., 1997), indicating that the problem is one of iron availability rather than concentration alone: primary productivity may be limited by lack of the bioavailable fraction of iron rather than of iron as a whole.

Algal experiments are normally carried out using culture media in which the iron (and other metals) speciation is carefully controlled by metal buffers containing high concentrations of EDTA and metals, (e.g., Sunda and Huntsman, 1995). Under these conditions, the $\mathrm{pFe}^{\prime}\left(\left[\mathrm{Fe}^{\prime}\right]\right.$ is the concentration of inorganic iron) is controlled and set at a constant level by the presence of a high concentration of iron and excess of EDTA. The supply of iron to the cell is then automatically related to the concentration of free iron as the EDTA bound iron is not directly available.

The mechanism by which iron is taken up by algae in the natural system is not yet fully established. However, recent data indicates that iron uptake by eukaryotic algae (diatoms) is improved when complexed by protoporphyrins, whereas prokaryotic algae (as exemplified by cyanobacteria) better take up siderophore-bound iron (Hutchins et al., 1999). This is consistent with a mechanism in which the eukaryotic algae use an uptake system based on iron-reduction at the cell surface followed by ionic iron transport (e.g., Soria-Dengg and Horstmann, 1995; Lynnes et al., 1998). The uptake of organic iron(III) would tend to be slow if iron is organically complexed due slow kinetics of complex dissociation (Hudson and Morel, 1990).

The oceanic water column contains low concentrations of ligands (between 0.2 and $8 \mathrm{nM}$ (van den Berg, 1995; Rue and Bruland, 1997), which form stable complexes with iron. The kinetics of the complexation reaction with these ligands is quite slow, reaching equilibrium at times between $15 \mathrm{~min}$ and several hours (van den Berg, 1995; Rue and Bruland, 1997; Witter and Luther, 1998). At such slow reaction rates, it is not likely that algae would benefit much from the dissociation of organic iron in the diffusion layer surrounding the cells to enhance pFe'-controlled iron uptake. On the other hand, a direct uptake of the already organically complexed iron would not be affected by such slow kinetics.
Complexation of iron by natural complexing ligands could therefore possibly convert iron to a bioavailable form. This effect would be overlooked in the conventional, EDTA-controlled cultures due to its domination of iron complexation, unless large amounts of siderophores are produced, which could possibly outcompete the EDTA, like in cyanobacteria cultures (Wilhelm and Trick, 1994).

To investigate the possibility of the availability of natural organic iron species we cultured algae in seawater without addition of a metal-ion buffer (like EDTA), at low- and high-iron concentrations. The ubiquitous coccolithophore Emiliania huxleyi was used as test organism: this species is an important component of oceanic algal blooms; it manages to maintain its chlorophyll content at low-iron levels by reducing its cell volume (Muggli and Harrison, 1996). The chemical speciation of iron, including the concentration of iron-complexing ligands, was determined by cathodic stripping voltammetry (CSV) with ligand competition. The growth of the algae in the seawater was monitored, and bioassays were used to monitor any effects of adding iron.

\section{Methods}

\subsection{Reagents}

Milli-Q-water (MQ; resistance 18.2 $\mathrm{M} \Omega$ ) was used for reagent preparation and for rinsing. Hydrochloric acid, ammonia and methanol (Merck, AnalaR grade) were purified by sub-boiling distillation using a quartz, cold-finger distillation unit. The $\mathrm{pH}$ of a 1 M solution of $N$-2-hydroxylethylpiperazine- $N N^{\prime}-3$ propanesulphonic acid (HEPPS) buffer (BDH product) was adjusted with ammonia to give $\mathrm{pH} 8$ when diluted 100-fold with seawater. Contaminating trace metals were removed by equilibration with $50 \mu \mathrm{M}$ manganese oxide followed by filtration $(0.2 \mu \mathrm{m})$. A $0.02 \mathrm{M}$ 1-nitroso-2-naphtol (NN) solution in methanol was used without further purification. A stock solution of $0.4 \mathrm{M}$ potassium bromate (AnalaR product) was prepared in MQ and cleaned by equilibration with $\mathrm{NN}(20 \mu \mathrm{M})$ at pH8 (using HEPPS, 5 $\mathrm{mM}$ ), followed by extraction using a Sep-Pak C18 cartridge (activated with methanol). A stock solution of $10^{-6} \mathrm{M} \mathrm{Fe}(\mathrm{III})$, was prepared in $0.01 \mathrm{M}$ hydro- 
chloric acid, using a standard iron solution (BDH SpectrosoL); this solution also contained $2.8 \mathrm{mM}$ nitric acid.

\subsection{Equipment}

An Autolab voltammeter (Eco Chemie, The Netherlands) was used for the voltammetric analyses, in conjunction with a Metrohm (Herisau, Switzerland) $663 \mathrm{VA}$ electrode stand (in the hanging mercury drop mode, drop size approximately $0.52 \mathrm{~mm}^{2}$ ). The reference electrode was double-junction $\mathrm{Ag} /$ saturated $\mathrm{AgCl}$ in $3 \mathrm{M} \mathrm{KCl} / 3 \mathrm{M} \mathrm{KCl}$, and the counter electrode was glassy carbon. During the adsorption, step solutions were stirred by a PTFE rod rotating at $2500 \mathrm{rpm}$. The voltammeter was controlled by an IBM-AT compatible computer.

\subsection{Cultures of E. huxleyi}

An axenic culture of E. huxleyi (Lohmann PCC No. 92 and 92d, isolated by Hay and Muller, Plymouth Marine Laboratory) was maintained in $\mathrm{f} / 2$ medium. At day 7, the culture was in the exponential phase, and $1 \mathrm{ml}$ of the culture was used to inoculate $1 \mathrm{l}$, filtered $(0.2 \mu \mathrm{m})$ sea water originating from the North Atlantic, enriched with nitrate and phosphate ( $\mathrm{N}$ and $\mathrm{P}$; prepared from Merck, Analar grade, $\mathrm{NaNO}_{3}$ and $\mathrm{Na}_{2} \mathrm{HPO}_{4}\left(\mathrm{H}_{2} \mathrm{O}\right)_{2}$ salts without further purification) to final concentrations of 176 and 7.26 $\mu \mathrm{M}$, respectively (equivalent to $\mathrm{f} / 10$ concentrations). EDTA and trace metals/vitamins and cell numbers of the $\mathrm{f} / 2$ culture were thus diluted by a factor of 1,000 into this "first-generation" culture. The iron concentration was rather high $(11.7 \mathrm{nM})$ in the firstgeneration culture due to carryover from the $f / 2$ medium. Therefore, the first-generation algal culture was sub-cultured $(2 \mathrm{ml}$ of culture into $11 \mathrm{~N} / \mathrm{P}$-enriched sea water; $\mathrm{f} / 10$ concentrations of $\mathrm{N}$ and $\mathrm{P}$ ) to give a second-generation culture, which was used here. The iron contribution from that added to the culture medium was thus minimised to $\sim 23 \mathrm{pM}$, below the culture media blank.

The sea water used for these experiments was obtained from the North Atlantic, filtered $(0.2 \mu \mathrm{m})$, and equilibrated overnight with manganese oxide (50 $\mu \mathrm{M})$ to remove contaminating trace metals, and filtered again $(0.1 \mu \mathrm{m}) . \mathrm{N}$ and $\mathrm{P}$ were added, and the sea water was UV-digested $(\sim 3 \mathrm{~h})$ to remove organic matter, and filtered $(0.1 \mu \mathrm{m})$ by pumping through an in-line, sealed filter holder for sterilisation. The water was inoculated with $2 \mathrm{ml}$ of a first-generation stock culture (experiment 1). In a second experiment, the sea water was UV-digested prior to the nutrient addition and the manganese oxide equilibration, which resulted in a lower background concentration of iron. Half of this medium was used as a control (not inoculated with algae), and the other half was inoculated with $4.5 \mathrm{ml}$ of a first-generation culture.

\subsection{Culturing conditions}

The cultures were grown at $15^{\circ} \mathrm{C}$, under continuous illumination (illuminated Cooled Incubator, Mercia Scientific). Cells were counted using an Inverted Biological Microscope (Wild M40, Wild Heerbrugg, Switzerland) (Lund et al., 1958). Acid-cleaned and sterilised polycarbonate bottles (Nalgene) were used to grow the algae, which were conditioned overnight using $50 \mathrm{ml}$ of the medium to minimise any iron adsorption from the sea water. Pipette tips with an air-filter (Aeroseal Gold filter, Fisher Brand) were used to inoculate the algae. Equipment in contact with the culturing solutions (bottles, pipette tips, filtration system, etc.) was sterilised after adding a small volume of MQ by using a microwave oven (600 W, for $20 \mathrm{~min}$ ), instead of an autoclave to avoid trace metal contamination via the steam and to prevent possible precipitation of carbonate species (Price et al., 1989). Sample manipulations were carried out in a laminar flow hood with HEPPA-filtered air. The cultures were axenic for periods of at least 1 month as demonstrated by absence of bacteria growth on subsamples of the first-generation cultures in LB medium, and confirmed by microscope.

\subsection{Ligand extraction from cells}

Twenty milliliters of a 1.5-month-old, secondgeneration, low-iron culture were centrifuged $\sim 5$ min in a acid-cleaned Teflon centrifuge tube container. The supernatant was removed using an acidcleaned and sterilised pipette tip and the concentrate was diluted in UV-digested and filtered $(0.1 \mu \mathrm{m})$ sea 
water. The cells were centrifuged again, and resuspended in the same water by mixing the solution, which caused the solution to become green; the suspension was and frozen $\left(-20^{\circ} \mathrm{C}\right)$ for a week to cause the cells to lyse. Sub-samples of this lysed cell suspension stock were diluted in UV-digested, filtered sea water and titrated with iron.

\subsection{Determination of iron speciation}

Iron was determined by catalytic CSV using bromate (0.04 M final concentration) as oxidant (Aldrich and van den Berg, 1998). The concentration of dissolved iron was determined in acidified $(\mathrm{pH} \sim 2)$ and UV-digested ( $\sim 5 \mathrm{~h}$, in acid-cleaned silica tubes) sample aliquots for experiment 1; a 10-ml sample aliquot was then pipetted into the voltammetric cell, the $\mathrm{pH}$ was approximately neutralised using ammonia and subsequently set to $\mathrm{pH} 8$ using HEPPS buffer $(100 \mu \mathrm{l}$ of the $1 \mathrm{M}$ stock solution), and $\mathrm{NN}$ $(10 \mu \mathrm{M} N \mathrm{NN})$ and bromate $(0.04 \mathrm{M})$ were added. Dissolved oxygen was removed by 300 -s purging with nitrogen; a 60-s adsorption time was used, at an adsorption potential of $-0.3 \mathrm{~V}$, the scan was carried out using sampled DC, $4 \mathrm{mV}$ step height, 10 steps $\mathrm{s}^{-1}$. The iron concentrations in samples from experiment 2 were determined without UV-digestion, using a much higher concentration of $\mathrm{NN}(50 \mu \mathrm{M})$ to increase the detection window; the $\mathrm{NN}$ was equilibrated $(1 \mathrm{~h})$ with the sample to ensure dissociation of virtually all iron from natural complexes. The voltammetric parameters were the same as for experiment 1 . The difference in the detected iron concentrations between the two methods was insignificant $(<10 \%)$. Fe(III) standard (BDH, Spectrosol grade) was used for the titrations and iron additions.

The iron-complexing ligands were determined by titrations with iron with detection of labile iron by CSV using ligand competition against the analytical ligand (NN) to evaluate the complex stability (Gledhill and van den Berg, 1994; van den Berg, 1995). Titrations were carried out at $\mathrm{pH} 8.0$, using HEPPS $\mathrm{pH}$ buffer and $5 \mu \mathrm{M}$ NN. Equilibration between added iron, $\mathrm{NN}$, and the natural complexing ligands was done overnight, and the bromate $(1 \mathrm{ml}$ of the $0.4 \mathrm{M}$ stock solution) was added $3 \mathrm{~min}$ before the first voltammetric scan.
Culture samples were filtered by gravity filtration (to avoid cell damage) through either $0.1-$ or $0.2-\mu \mathrm{m}$ membrane filters (polycarbonate, Millipore), using a polycarbonate filter apparatus (Sartorius) prior to the iron speciation analysis.

\subsection{Theory}

Ligand concentrations $\left(C_{\mathrm{L}}\right)$ and conditional stability constants $\left(K_{\mathrm{FeL}}^{\prime}=[\mathrm{FeL}] /\left(\left[\mathrm{Fe}^{3+}\right]\left[\mathrm{L}^{\prime}\right]\right)\right)$ were calculated by linear least-squares regression of the data according to the "van den Berg/Ruzic linearisation”, (Ruzic, 1982; van den Berg, 1982):

$$
\begin{aligned}
{\left[\mathrm{Fe}_{\text {labile }}\right] /[\mathrm{FeL}]=} & {\left[\mathrm{Fe}_{\text {labile }}\right] / C_{\mathrm{L}}+\left(\alpha_{\mathrm{Fe}^{\prime}}+\alpha_{\mathrm{FeNN} 3}\right) } \\
& /\left(C_{\mathrm{L}} K_{\mathrm{FeL}}^{\prime}\right)
\end{aligned}
$$

Here, $\log \alpha_{\mathrm{Fe}}^{\prime}=10$ (Hudson and Morel, 1990), and $\log \alpha_{\mathrm{FeNN} 3}=12.5$ (using $\log \beta_{\mathrm{FeNN} 3}^{\prime}=28.39$ ) (Gledhill and van den Berg, 1994).

\section{Results}

Preliminary experiments were carried out to verify whether $E$. huxleyi would grow in sea water while supplemented only with $\mathrm{N}$ and $\mathrm{P}$ (Leal et al., 1999) using "first-generation", cultures, sub-cultured by dilution of a $f / 2$ stock culture into sea water. The "first-generation", cultures demonstrated reproducible growth, with a standard deviation of 5-8\% (Leal et al., 1999). However, the iron carryover (11.7 $\mathrm{nM}$ ) into these cultures was high. For this reason, these cultures were sub-cultured again into sea water supplemented only with $\mathrm{N}$ and $\mathrm{P}$.

Two (second generation) cultures of E. huxleyi were incubated in sea water enriched with nitrogen and phosphate containing iron concentrations of 5.4 $\mathrm{nM}$ (= "high-iron" culture) and $1.3 \mathrm{nM}$ (=" "lowiron" culture). Algal growth was very poor in the low-iron culture, the cell numbers increasing from 500 cells $\mathrm{ml}^{-1}$ at incubation to 1200 cells ml ${ }^{-1}$ over 14 days (growth rate $\sim 0.1$ days $^{-1}$ ) (Fig. 1). The high-iron culture (Table 1) was in exponential growth from days 2-7, achieving a cell concentration of $52,000 \mathrm{ml}^{-1}$ at day 12 (growth rate 0.4 days $^{-1}$ ). This growth rate was much less than that $(1-1.5$ days $^{-1}$ ) in iron-replete (first-generation) cultures (Leal et al., 1999). 

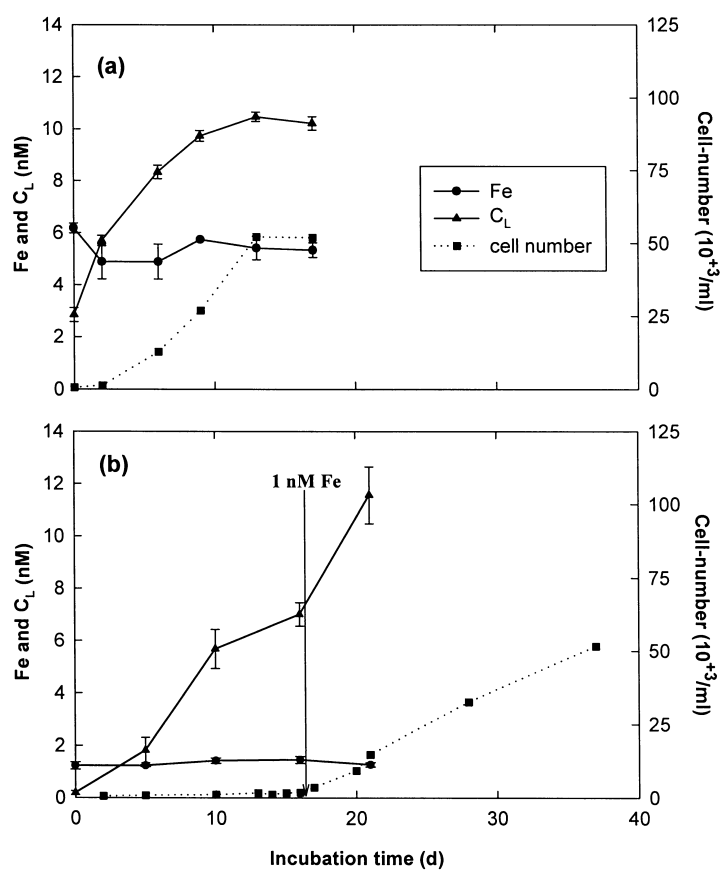

Fig. 1. Dissolved iron $(\mathrm{Fe})$, iron-complexing ligands $\left(C_{\mathrm{L}}\right)$ and cell numbers in Emiliania huxleyi cultures grown in UV-oxidised sea water supplemented with nutrients, at two iron concentrations. (a) High iron (5.4 nM), (b) low iron (1.3 nM). A 1-nM iron addition is indicated in (b).

The poor growth in the low-iron culture suggested that this culture was iron limited. To verify this, an iron addition of $1 \mathrm{nM}$ was made after 14 days. This iron addition was greater than the estimated iron solubility of $\sim 0.7 \mathrm{nM}$ (Sunda and Huntsman, 1995) but less than the ligand concentration in the sample: it is likely that the iron would initially have been present as inorganic species, perhaps - to some extent- beginning to form a colloid. Subsequently, over a period of $15 \mathrm{~min}$ to an hour, the iron would have become complexed by the natural ligands, thus lowering the inorganic iron concentration again. The iron addition was followed by an increase in growth, ultimately producing 50,000 cells $\mathrm{ml}^{-1}$ over the next 14 days, and reaching a growth rate of $\sim 0.5$ days $^{-1}$ (Table 2). The increase confirmed that the culture was iron-limited, which was surprising considering that a background iron concentration of $\sim 1 \mathrm{nM}$ would not normally be considered to limit photosynthesis in sea water, and the increase in the iron concentration represented only a doubling of the original iron concentration.

Growth in the high-iron culture levelled off at 50,000 cells $\mathrm{ml}^{-1}$ after an incubation time of 12 days (Fig. 1). This is less than the number of cells (150-200,000 cells $\mathrm{ml}^{-1}$ ) achieved in iron-replete (first-generation) cultures when phosphate became limiting (Leal et al., 1999). An iron addition of $9 \mathrm{nM}$ was made to verify whether even the high-iron culture (containing $5 \mathrm{nM}$ iron) could be iron-limited. This iron addition would have probably initially caused a tendency to form colloidal iron; however, the ligand concentration in this culture $(\sim 10 \mathrm{nM})$ was sufficiently high to complex most added iron thus, lowering the inorganic iron concentration again. Unexpectedly, this caused the culture growth to take off again, increasing cell numbers to 330,000 cells

Table 1

Iron speciation in the high_iron $(5.4 \mathrm{nM} \mathrm{Fe})$ culture prepared in UV-oxidised sea water. A 9-nM iron addition was made after 17 days. The day-0 measurement is for the sea water prior to inoculation

\begin{tabular}{|c|c|c|c|c|c|c|c|c|}
\hline $\begin{array}{l}\text { Time } \\
\text { (days) }\end{array}$ & $\begin{array}{l}\text { Cells } \\
\left(10^{3} \mathrm{ml}^{-1}\right)\end{array}$ & $\begin{array}{l}\text { Growth rate } \\
\left(\text { day }^{-1}\right)\end{array}$ & $\mathrm{Fe}(\mathrm{nM})$ & $C_{\mathrm{L}}(\mathrm{nM})$ & $\log K_{\mathrm{FeL}}^{\prime}$ & $\mathrm{FeL}(\mathrm{nM})$ & $\mathrm{Fe}^{\prime}(\mathrm{pM})$ & $\begin{array}{l}\text { Organic } \\
\mathrm{Fe}(\%)\end{array}$ \\
\hline 0 & 0.52 & & $6.2 \pm 0.2$ & $2.8 \pm 0.3$ & - & - & - & - \\
\hline 2 & 1.19 & 0.4 & $4.9 \pm 1.7$ & $5.7 \pm 0.2$ & $21.5 \pm 0.2$ & 4.8 & 19 & 99.6 \\
\hline 6 & 12.7 & 0.6 & 4.9 & $8.3 \pm 0.3$ & $21.5 \pm 0.2$ & 4.9 & 4.5 & 99.9 \\
\hline 9 & 26.9 & 0.25 & $5.7 \pm 0.1$ & $9.7 \pm 0.2$ & $21.5 \pm 0.1$ & 5.7 & 4.7 & 99.9 \\
\hline 13 & 52.1 & 0.17 & $5.4 \pm 0.5$ & $10.5 \pm 0.2$ & $21.5 \pm 0.1$ & 5.4 & 3.5 & 99.9 \\
\hline 17 & 51.9 & 0.0 & $5.3 \pm 0.3$ & $10.2 \pm 0.3$ & $21.5 \pm 0.1$ & 5.3 & 3.5 & 99.9 \\
\hline 18 & 84.1 & 0.5 & - & - & - & - & - & - \\
\hline 19 & 185.6 & 0.8 & - & - & - & - & - & - \\
\hline 28 & 332.0 & 0.06 & - & - & - & - & - & - \\
\hline
\end{tabular}


Table 2

Iron speciation in the low-iron culture, prepared in UV-oxidised sea water. The day-0 measurement is for the sea water prior to inoculation. An iron addition of $1 \mathrm{nM} \mathrm{Fe}(\mathrm{III})$ was made after 14 days

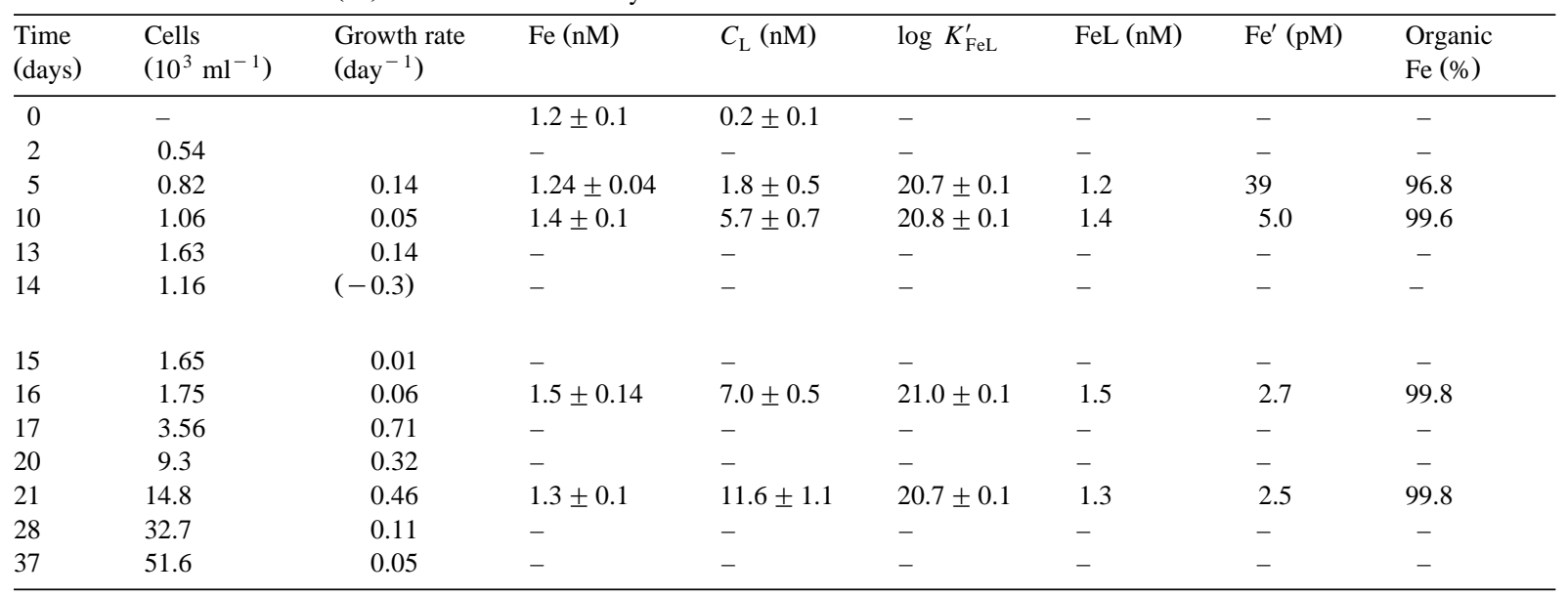

$\mathrm{ml}^{-1}$ — suggesting that "high-iron" culture was also iron-limited.

Neither of these second-generation cultures grew well and had a long lag phase. It is likely that the absence of vitamins may have played a role, in addition to the apparent iron limitation. However, the increased growth with the iron additions indicated that the freshly added iron was crucial in stimulating the culture to grow. An explanation for the iron stimulation of these cultures could be that the iron originally present in the culture medium was not available to the algae. The cell numbers in these cultures were similar to those occurring in the natural system where levels of 10,000 cells $\mathrm{ml}^{-1}$ are known to occur in major blooms in the North Atlantic (Holligan et al., 1993).

\subsection{Variation of the concentration and chemical speciation of iron in the cultures}

The dissolved iron concentration did not vary significantly during the long incubation periods: 5.4 $\pm 0.5 \mathrm{nM}$ for the first 14 days of the high-iron culture, and $1.3 \pm 0.1 \mathrm{nM}$ for the first 10 days of the low-iron culture. The iron concentration also remained constant in a control bottle (not inoculated) containing $1.3 \mathrm{nM}$ iron, indicating that there was no significant adsorption on the bottle walls.
Interestingly, the 1-nM iron addition made to the low-Fe culture could not be detected in the dissolved iron fraction 2 days later, indicating that the added iron had been rapidly taken up (by adsorption or absorption) by the algae. Iron additions $(2 \mathrm{nM})$ made during the IronexII experiment were also removed from the water within 2 days but in that case, the iron could have precipitated as a colloidal or particulate fraction in addition to uptake by microorganisms. The addition of $1 \mathrm{nM}$ iron to this experiment was less than the excess ligand concentration; complexation should, therefore, have solubilised any colloidal iron-hydroxides that might have formed initially. The disappearance of the freshly added iron may have been caused by the rapid removal of microorganisms, possibly as luxury uptake to tide the organisms over a period of low iron availability. Assuming an Fe:C ratio of $\sim 2-10 \mu \mathrm{mol} \mathrm{mol}{ }^{-1}$ (Sunda and Huntsman, 1997) and a cellular organic carbon content of E. huxleyi of $12 \mathrm{pg}(1 \mathrm{pmol} \mathrm{C})$ (Van Bleijswijk et al., 1994), an iron assimilation of 100-500 pM was required to increase the cell numbers to 50,000 cells $\mathrm{ml}^{-1}$. A major fraction (10-50\%) of the added iron may was, therefore, ultimately used by the algae.

Although the increase in iron concentration was not detectable after 2 days, the culture continued to grow for 14 days after the iron addition, the cell numbers doubling 5-6 times. The freshly taken-up 
iron must, therefore, have been stored by the microorganisms and was available for an extended period of growth.

\subsection{Organic iron-complexing ligands}

The chemical speciation of iron was investigated to evaluate whether this could explain the postulated
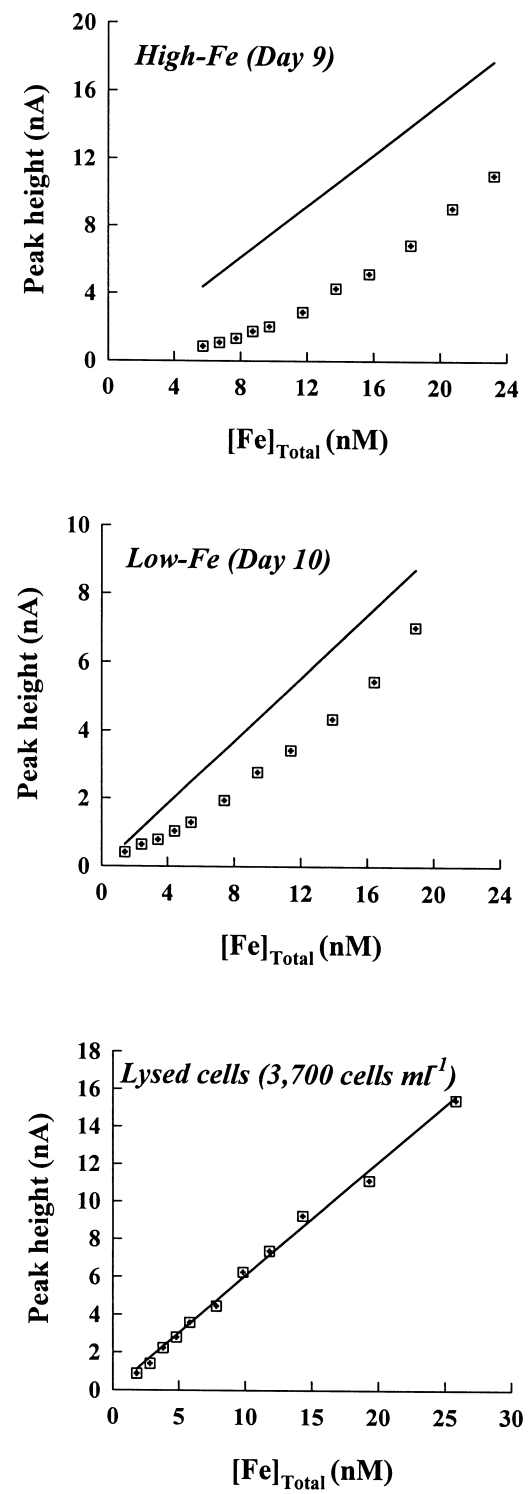

Fig. 2. Iron-complexing ligand titrations of high-Fe (day 9, top) and low-Fe (day 10, centre) cultures, and of a suspension of lysed cells (equivalent to 3700 cells $\mathrm{ml}^{-1}$ ) are shown on the left; linearised plots of the data are shown on the right; the lysed cells titration showed no evidence of iron complexation. unavailability of iron in sea water. The concentration of iron-complexing ligands in the UV-digested water of the low-Fe culture was initially very low $(0.2 \pm 0.1$ $\mathrm{nM}$, Table 1). The ligand concentration increased over the first 10 days of the incubation period, levelling off at $\sim 5.7 \mathrm{nM}$ (Fig. 1). The ligand concentration increased again in a relatively rapid rate after the 1-nM iron addition (over 5 days from 7 to
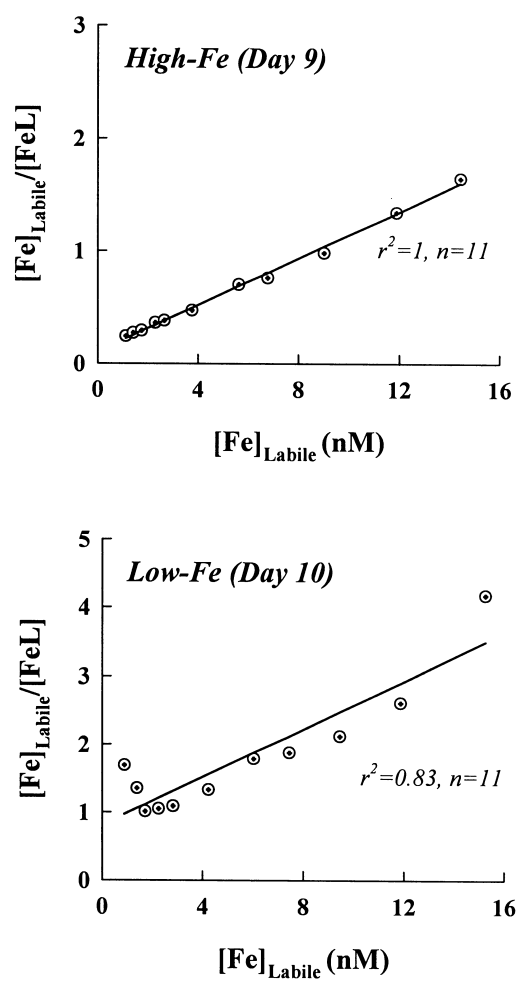
$12 \mathrm{nM}$ (Table 1, Fig. 1). The ligand concentration in the high-iron culture increased more rapidly than in the low-iron culture, from 3 to $9.7 \mathrm{nM}$ over the first 10 days of the culture, and levelling of at $10.3 \mathrm{nM}$ after 14 days. A ligand concentration of $3 \mathrm{nM}$ was produced within the first 2 days in this culture when the cell numbers were still low, increasing from 500 to 1000 cells $\mathrm{ml}^{-1}$. Representative titrations of the ligands in the low and high-Fe cultures are shown in Fig. 2. The plots of the peak height (representing labile iron), as a function of the total iron concentration, were curved - indicating iron complexation. The linearised plots of the data showed no evidence of downward curvature at low-iron concentrations, suggesting that the complexation was dominated by a single ligand.

The ligand production on a cellular basis was greatest during the beginning phase of these cultures as the cell numbers were initially very low (500-1000 cells $\mathrm{ml}^{-1}$ ). Assuming a molecular weight of 500 for the iron-complexing ligands (this is the approximate molecular weight for cyanobacterial siderophores) (Trick and Kerry, 1992), the production of $6 \mathrm{nM}$ of ligands was equivalent to $3 \mu \mathrm{g}^{-1}$ of organic matter. Assuming a cellular weight of 24 pg (algal

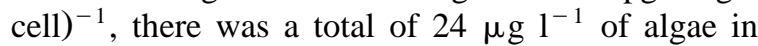
the culture, indicating that the ligands represented a significant fraction ( $25 \%$ using these estimates) of the organic matter produced as algal mass (this fraction would be correspondingly smaller for a lower molecular weight of the ligands). Although this amount may seem high, large amounts of copperbinding ligands (10-20 $\mathrm{nM}$ over the first 2 days of a first-generation culture) are known to be released by E. huxleyi at similarly low cell numbers (300-600 cells $\mathrm{ml}^{-1}$ ) (Leal et al., 1999). The copper-complexing ligands are thought to be thiol compounds; the molecular weight of the iron-complexing ligands may be much less than the 500 assumed here if they have the same nature.

\subsection{Ligands from lysed cells}

One possibility is that the ligands were released inadvertently from the algae as a result of cell lysis during filtration or as a result of cell-leakage into the medium. To eliminate this possibility, an algal suspension containing 92,000 cells $\mathrm{ml}^{-1}$ (from a 1.5- month-old, second generation culture) was lysed by freezing and added to organic-free (UV-digested) sea water to final, nominal cell concentrations of 3700 and 6700 cells $\mathrm{ml}^{-1}$, and titrated with iron. The titration gave a linear response (Fig. 2) showing that iron was not complexed, which indicates that the organic matter contained in the algae could not be a major source of the ligands in the culture filtrates. It is possible that any ligands released from the lysed cells were already saturated with iron, and, therefore, did not show up as free ligands. However, this would have resulted in a linear titration with an offset on the $X$-axis (the iron concentration) and there was no evidence of this. Alternatively, it is possible that freezing was not sufficient to cause the cells to lyse, or that passage through the gut of grazers is necessary to release the ligands. Cell lysis by freezing is not a good model for lysis by grazing because, in this process, the cell contents pass through an acidic gut, an action that may release iron and other complexed metal species, and release free ligands. This experiment, therefore, only shows that there are no free ligands in cells damaged by, for instance, sloppy feeding.

\section{Discussion}

Both cultures (low and high iron) had a high concentration of inorganic iron at inoculation because the complexing ligands originally present in the sea water had been destroyed by UV digestion: $\sim 1 \mathrm{nM}$ for the low-iron culture, and $\sim 3.4 \mathrm{nM}$ for the high-iron culture. This iron may have been colloidal initially until it was complexed by the organic ligands that were produced by the algae within 1-2 days. The initial inorganic iron concentrations was apparently for growth in the high-iron culture; however, the initial iron concentration in the low-iron culture resulted in stunted growth.

The production of iron-complexing ligands was a common feature of these cultures, either at low- or high-iron concentrations; the ligand production is similar to that of copper-complexing ligands at lowand high-copper concentrations (Leal et al., 1999). Both cultures (low- and high-iron) became ironlimited as demonstrated by enhanced growth upon iron additions. The enhanced growth indicates that the initial iron was not available to the microorgan- 
isms even though it was present at a high concentration, whereas the freshly added iron was available. The iron in the cultures occurred as organic complexes at the time of the iron addition; whereas, the freshly added iron would have occurred for a brief period (up to $\sim 1 \mathrm{~h}$ ) as inorganic iron until it was complexed by the organic ligands (equilibration with the natural ligands can take several hours, Gledhill and van den Berg, 1994). These findings suggest that the organically-complexed iron was poorly available to E. huxleyi, whereas the freshly added, inorganic iron was readily available. This finding is consistent with the predicted poor availability of organically complexed iron because of the slow rates of complex dissociation (Hudson and Morel, 1990), and with the recent finding that strongly complexed (by siderophore-type ligands) iron is available to cyanobacteria but not to eukaryotic algae (Hutchins et al., 1999). However, on the whole, it is likely that the organically complexed iron is more available, albeit slowly, than colloidal precipitates that would form in their absence and that would rapidly remove iron from solution, because, otherwise, these algae would have no apparent reason to produce the ligands.

An inorganic iron concentration buffered with EDTA at $2 \mathrm{pM}$ is thought to be necessary to sustain the growth of E. huxleyi at a typical oceanic growth rate of 0.5 days $^{-1}$ (Sunda and Huntsman, 1995). The concentration of inorganic iron dropped to $19 \mathrm{pM}$ at day 2 of the low-iron incubation, to $4.5 \mathrm{pM}$ at day 6 , and to $3 \mathrm{pM}$ over the subsequent period (Table 2); in the high-iron culture, the inorganic iron concentration dropped to $5 \mathrm{pM}$ at day 10 , and after the fresh iron addition, it dropped again after 2 days to 2.7 $\mathrm{pM}$, and then to $2.5 \mathrm{pM}$ over the next 6 days. These inorganic iron concentrations were, therefore, ultimately similar to the minimum amount required to sustain growth, although initially their concentrations would have been greater. The poorer-than-expected growth in the cultures may be caused by (i) differences in cultured species, (ii) systematic errors in the measurement of organic iron complexation that may have caused the calculated inorganic iron concentrations to be greater, or (iii) by an iron contribution from complex dissociation of EDTA-bound iron (present at high concentrations) in the algal diffusion layer in EDTA-controlled cultures.
The finding that the organically complexed iron was poorly available suggests that the produced ligands do not have the function expected of siderophores (even though the complex stability is similar), which is to make the metal more available. The iron-stimulated growth continued even when the added iron was no longer detectable - indicating that this iron had been stored by the microorganisms. A motive for ligand production by the microorganisms is, therefore, not to make the iron more available, but probably to maintain the iron in solution and prevent its precipitation due to colloid formation. This mechanism is supported by the further production of ligands when more iron was added, in response to the iron addition (Table 2 and Fig. 1), taking the ligand concentration in the low-iron culture to $11 \mathrm{nM}$ : such production would not fit with the siderophore function of the ligands (which would be produced in periods of iron shortage) but does fit with an intention of retaining inorganic iron in solution. This means that a feedback mechanism must exist to produce ligands, which is triggered by increased free iron concentrations. A clue to the mechanism may be that the ligands are released after the iron has been taken up: after all, by the time the organisms begin to release complexing ligands in response to the iron addition, they will already have taken up at least some of the iron. The arrival of the iron in the organisms may thus stimulate the production of iron-complexing ligands.

The ligand production, in response to iron additions, is analogue to the production of thiols and copper-complexing ligands by $E$. huxleyi in response to copper additions (Leal and van den Berg, 1999). The concentrations of the thiols and the copper-complexing ligands were much greater (at $30-60 \mathrm{nM}$ ) than those of the iron-complexing ligands, so it is unlikely that the identical ligands are involved. The culture also gave enhanced growth at low copper additions (Leal and van den Berg, 1999) but this effect was minor compared to the growth stimulation caused by the iron additions.

The poor availability of the iron complexed by the natural ligands explains why these cultures require repeated iron additions to reach high cell numbers, which is similar to the situation in iron-limited oceanic waters (Rue and Bruland, 1997). It shows that it is necessary to continually add "fresh" (in- 
organic) iron to fully utilize the major nutrients in sea water, something that tends to happen naturally in the North Atlantic as a result of a "titration" of the major nutrients with atmospheric iron. Thus, it is possible that iron continues to limit algal growth also when it is present in the sea water at an apparently high concentration.

These cultures in nutrient-supplemented sea water grew quite poorly, and required a lag phase of several days, still growing slowly when supplemented with fresh iron. The growth rate levelled off before the major nutrients had been exhausted. It is possible that other metals (zinc, cobalt, or copper) contributed to the poor growth, in addition to the lack of vitamins. It is also possible that ligands were released along with other organic matter as a general response to the nutrient and vitamin poor medium. However, this would not explain the ligand release in response to the iron addition; it is more likely that the ligands were released in response to the iron limitation. The increased growth upon the iron addition also suggests that this, rather than other nutrients and vitamins, was the major limiting element.

More work may be required to further optimise the use of "realistic", minimalist, sea water cultures, supplemented with the bare minimum of nutrients, to investigate the effects and feed-backs of metal speciation and algae in the marine system.

The poor availability of the organically complexed iron and the requirement of repeated iron additions to maintain growth confirm the notion that inorganic iron is the major source of iron to these microorganisms (Sunda and Huntsman, 1997; Hutchins et al., 1999). Assuming this is generally true for more marine algae, it can be tentatively concluded that the organic complexation of iron is part of the cause of on-going iron limitation in the oceans.

\section{Acknowledgements}

This work was supported by a project (MERLIM) of the European Union within the Marine Science and Technology Program under contract No: MAS3CT95-0005, and by the PRIME project of the NERC (GST/02/1058).

\section{References}

Aldrich, A.P., van den Berg, C.M.G., 1998. Determination of iron and its redox speciation in seawater using catalytic cathodic stripping voltammetry. Electroanalysis 10, 369-373.

Coale, K.H., Johnson, K.S., Fitzwater, S.E., Gordon, R.M., Tanner, S., Chavez, F.P., Ferioli, L., Sakamoto, C., Rogers, P., Millero, F., Steinberg, P., Nightingale, P., Cooper, D., Cochlan, W.P., Landry, M.R., Constantinou, J., Rollwagen, G., Trasvina, A., Kudela, R., 1996. A massive phytoplankton bloom induced by an ecosystem-scale iron fertilization experiment in the equatorial Pacific Ocean. Nature 383, 495-501.

Gledhill, M., van den Berg, C.M.G., 1994. Determination of complexation of iron(III) with natural organic complexing ligands in sea water using cathodic stripping voltammetry. Mar. Chem. 47, 41-54.

Holligan, P.M., Fernandez, E., Aiken, J., Balch, W.M., Boyd, P., Burkill, P.H., Finch, M., Groom, S.B., Malin, G., Muller, K., Purdie, D.A., Robinson, C., Trees, C.C., Turner, S.M., Vanderwal, P., 1993. A biogeochemical study of the coccolithophore, Emiliania huxleyi, in the North Atlantic. Global Biogeochem Cycles 7, 879-900.

Hudson, R.J.M., Morel, F.M.M., 1990. Iron transport in marine phytoplankton: kinetics of cellular and medium coordination reactions. Limnol. Oceanogr. 35, 1002-1020.

Hutchins, D.A., Witter, A.E., Butler, A., Luther, G.W. III, 1999. Competition among marine phytoplankton for different chelated iron species. Nature 400, 858-861.

Johnson, K.S., Gordon, R.M., Coale, K.H., 1997. What controls dissolved iron concentrations in the world ocean? Mar. Chem. 57, 137-161.

Leal, M.F.C., Vasconcelos, M.T.S.D., van den Berg, C.M.G., 1999. Copper induced release of complexing ligands similar to thiols by Emiliania huxleyi in seawater cultures. Limnol. Oceanogr. 44, 1750-1762.

Lund, J.W.G., Kipling, C., Le Cren, E.D., 1958. The inverted microscope method of estimating algal numbers and the statistical basis of estimations by counting. Hydrobiologia 11, 144-170.

Lynnes, J.A., Derzaph, T.L.M., Weger, H.G., 1998. Iron limitation results in induction of ferricyanide reductase and ferric chelate reductase activities in Chlamydomonas reinhardtii. Planta 204 (3), 360-365.

Martin, J.H., Fitzwater, S.E., 1988. Iron deficiency limits phytoplankton growth in the northeast Pacific subarctic. Nature 331, 341-343.

Martin, J.H., Gordon, R.M., Fitzwater, S.E., Broenkow, W.W., 1989. VERTEX: phytoplankton/iron studies in the Gulf of Alaska. Deep-Sea Res. 35, 649-680.

Martin, J.H., Gordon, R.M., Fitzwater, S.E., 1990. Iron in Antarctic waters. Nature $345,156-158$.

Martin, J.H., Fitzwater, S.E., Gordon, R.M., 1991. Iron deficiency limits phytoplankton growth in Antarctic waters. Global Biogeochem. Cycles 4, 5-12.

Martin, J.H., Coale, K.H., Johnson, K.S., Fitzwater, S.E., Gordon, R.M., Tanner, S.J., Hunter, C.N., Elrod, V.A., Nowicki, J.L., Coley, T.L., Barber, R.T., Lindley, S., Watson, A.J., Van 
Scoy, K., Law, C.S., Liddicoat, M.I., Ling, R., Stanton, T., Stockel, J., Collins, C., Anderson, A., Bidigare, R., Ondrusek, M., Latasa, M., Millero, F.J., Lee, K., Yao, W., Zhang, J.Z., Friederich, G., Sakamoto, C., Chavez, J., Buck, K., Kolber, Z., Greene, R., Falkowski, P., Chisholm, S.W., Hoge, F., Swift, R., Yungel, J., Turner, S., Nightingale, P., Hatton, A., Liss, P., Tindale, N.W., 1994. Testing the iron hypothesis in ecosystems of the equatorial Pacific Ocean. Nature 371, 123-129.

Muggli, D.L., Harrison, P.J., 1996. Effects of nitrogen source on the physiology and metal nutrition of Emiliania huxleyi grown under different iron and light conditions. Mar. Ecol. Prog. Ser. 130 (1-3), 255-267.

Price, N.M., Harrison, G.L., Hering, J.G., Hudson, R.J., Nirel, P.M., Palenik, B., Morel, F.M.M., 1989. Preparation and chemistry of the artificial algal culture medium. Aquil. Biol. Ocean 6, 443-461.

Rue, E.L., Bruland, K.W., 1995. Complexation of iron(III) by natural organic ligands in the Central North Pacific as determined by a new competitive ligand equilibration/adsorptive cathodic stripping voltammetric method. Mar. Chem. 50, $117-$ 138.

Rue, E.L., Bruland, K.W., 1997. The role of organic complexation on ambient iron chemistry in the equatorial Pacific Ocean and the response of a mesoscale iron addition experiment. Limnol. Oceanogr. 42, 901-910.

Ruzic, I., 1982. Theoretical aspects of the direct titration of natural waters and its information yield for trace metal speciation. Anal. Chim. Acta 140, 99-113.

Soria-Dengg, S., Horstmann, U., 1995. Ferrioxamine-b and Fer- rioxamine-e as iron sources for the marine diatom phaeodactylum-tricornutum. Mar. Ecol. Prog. Ser. 127 (1-3), 269-277.

Sunda, W.G., Huntsman, S.A., 1995. Iron uptake and growth limitation in oceanic and coastal phytoplankton. Mar. Chem. 50, 189-206.

Sunda, W.G., Huntsman, S.A., 1997. Interrelated influence of iron, light and cell size on marine phytoplankton growth. Nature 390, 389-392.

Trick, C.G., Kerry, A., 1992. Isolation and purification of siderophores produced by cyanobacteria, Synechococcus sp. pcc-7942 and Anabaena variabilis atcc-29413. Curr. Microbiol. 24, 241-245.

van Bleijswijk, J.D.L., Kempers, R.S., Veldhuis, M.J., Westbroek, P., 1994. Cell and growth-characteristics of type-a and type-b of Emiliania huxleyi (prymnesiophyceae) as determined by flow-cytometry and chemical-analyses. J. Phycol. 30, 230-241.

van den Berg, C.M.G., 1982. Determination of copper complexation with natural organic ligands in seawater by equilibration with $\mathrm{MnO}_{2}$ : I. Theory. Mar. Chem. 11, 307-322.

van den Berg, C.M.G., 1995. Evidence for organic complexation of iron in seawater. Mar. Chem. 50, 139-157.

Wilhelm, S.W., Trick, C.G., 1994. Iron-limited growth of cyanobacteria: multiple siderophore production is a common response. Limnol. Oceanogr. 39, 1979-1984.

Witter, A.E., Luther, G.W., 1998. Variation in Fe-organic complexation with depth in the Northwestern Atlantic Ocean as determined using a kinetic approach. Mar. Chem. 62 (3-4), 241-258. 